Voix et Images

voixetimages

\title{
À propos d'Un matriarcat en procès
}

\section{Annette Hayward}

Volume 9, numéro 1, automne 1983

Guy Dufresne

URI : https://id.erudit.org/iderudit/200428ar

DOI : https://doi.org/10.7202/200428ar

Aller au sommaire du numéro

Éditeur(s)

Université du Québec à Montréal

ISSN

0318-9201 (imprimé)

1705-933X (numérique)

Découvrir la revue

Citer ce compte rendu

Hayward, A. (1983). Compte rendu de [À propos d'Un matriarcat en procès].

Voix et Images, 9(1), 155-157. https://doi.org/10.7202/200428ar d'utilisation que vous pouvez consulter en ligne.

https://apropos.erudit.org/fr/usagers/politique-dutilisation/ 


\title{
À propos' d'Un matriarcat en procès
}

\author{
par Annette Hayward, Université Queen's
}

Le lecteur qui achètera ce volume ${ }^{1}$ en croyant se procurer une analyse des romans canadiens-français les plus représentatifs de 1860 à 1960 sera saṇs doute vivement déçu d'y découvrir une étude du roman du terroir, genre romanesque qu'on confond souvent avec le roman de la terre et que tous les critiques situaient jusqu'à présent entre 1846 et la deuxième guerre mondiale.

$\mathrm{Au}$ lieu de définir ce qu'elle entend par roman du terroir afin de justifier ce choix de dates insolite et le fait d'inclure dans sa «liste» (qu'elle ne donne pas comme telle) ${ }^{2}$ nombre de romans dont la présence ici peut étonner, Janine Boynard-Frot évite tout simplement la question. Elle mentionne en passant que le «roman du terroir raconte, sur le mode de la pastorale qui correspond à un parti pris d'idéalisation de la vie rurale, l'histoire d'une alliance entre l'homme et la terre» (p. 33), ce qui décrit mal des romans comme La Scouine, Marie Calumet, Jeanne la fileuse ou Menaud, Maître-draveur (pour n'en citer que des plus connus), pourtant étudiés ici. N'ayant trouvé aucun roman du terroir entre 1952 et 1960 , l'auteure affirme que le genre «marque un net fléchissement à partir de 1952». Pourtant, si l'on inclut dans cette catégorie tout roman québécois traitant de la vie à la campagne, pourquoi ne pas continuer alors en analysant des œuvres telles que La Belle Bête (1959) et Une saison dans la vie d'Emmanuel (1965) de Marie-Claire Blais ou Les Grands-Pères (1971) de

1. BOYNARD-FROT, Janine, Un matriarcat en procès. Analyse systématique de romans canadiens-français. 1860-1960, Montréal, P.U.M., 1982.

2. Les romans étudiés ne sont jamais énumérés clairement dans le texte. L'auteure utilise des sigles qui renvoient à un appendice où lés cuures ne sont données ni par ordre alphabétique des titres (pour correspondre aux sigles) ni par ordre chronologique, mais par nom d'auteur. Le fait que "S» y désigne en même temps le Survenant et Sources, ou que "TA» s'applique non seulement à Trente arpents mais aussi, dans les deux tiers des cas, à $L a$ Terre ancestrale, $\mathrm{n}$ 'aide en rien la compréhension du lecteur. 
Victor-Lévy Beaulieu? Serait-ce par hasard un fort penchant anticlérical ${ }^{3}$ qui la pousserait à choisir 1960 afin de pouvoir terminer sa présentation sociologique en affirmant que le clergé québécois, tenu dès lors en dehors de l'enjeu politique, "entraîna(i)t avec lui son (sic) roman dans sa retraite» (p. 30)?

Quant au «matriarcat» dont on annonce le procès, il n'en sera jamais question; le texte ne parle que de «système patriarcal» et de «femmesobjets». Faut-il en conclure que la société d'entre 1860 et 1960 aurait été une société matriarcale? Ou que ces livres présenteraient en apparence une société matriarcale? Ou... Toutes les spéculations sont permises car Janine Boynard-Frot a décidé de garder pour elle le secret de ce titre qui frise la fausse représentation.

Pourtant, le roman du terroir viu à travers la sociocritique, la sémiotique et la critique féministe, quel sujet en or!

Les objectifs proposés sont on ne peut plus louables et un lecteur averti se doute vite des conclusions tranchantes que vont permettre ces romans qui véhiculent souvent l'idéologie agriculturiste à l'état pur. ${ }^{4} \mathrm{Si}$ on savait déjà que la ville y est l'équivalent de l'enfer et la campagne du paradis, il est toujours bon de le montrer d'une façon systématique et précise... Et si une idéologie aussi traditionaliste se devait d'être également paternaliste, les ramifications de ce paternalisme que l'auteure dépistera au sujet du vêtement, de la prise de la parole ou de la «valeur» morale, intellectuelle et énergétique du personnage féminin sont tout à fait révélatrices. ${ }^{5}$

Malheureusement, il arrive trop souvent que les ouvres disparaissent derrière les grilles qu'on leur applique. À force de fournir chiffres, tableaux et carrés sémiotiques, l'auteure ne trouve même plus l'espace nécessaire pour citer les titres des romans ${ }^{2}$ ou les noms des héros décrits par ses statistiques. Il faut donc lui faire presque aveuglément confiance quand elle fait des affirmations du genre : «En outre, en dépit du faible pourcentage de départs des sujets féminins $(16,4 \%)$ par rapport à l'ensemble des départs, la mort, consécutive au déplacement, frappe $45,4 \%$ des sujets féminins qui se disjoignent de l'espace campagne tandis qu'elle n'affecte qu'un faible pourcentage $(16 \%)$ de sujets masculins se livrant à des opérations identiques» (p. 40). Comment s'y résoudre, pourtant, lorsqu'elle dit sans

3. Voir également, à la page 17 , le véritable réquisitoire contre la confession comme "système de répression». À notre connaissance, ce rituel n'a rien de spécifiquement canadien et n'a nullement cessé de se pratiquer en 1960.

4. La Terre d'Ernest Choquette, par exemple, dira ouvertement que les Canadiens français ne sont pas doués pour l'industrie et doivent s'en tenir à l'agriculture.

5. Il ne faudrait pas croire que cette perspective paternaliste soit particulière aux auteurs des romans du terroir ou aux tenants de l'idéologie agriculturiste, cependant. Parmi les ennemis les plus acharnés du régionalisme au début du siècle, tel Victor Barbeau, se trouvaient des gens on ne peut plus rébarbatifs au féminisme. 
hésitation qu'Angélina Desmaraịs est l'héroïne du Survenant et Charlot le héros de La Scouine? Ou quand elle cite en exemples des personnages secondaires à la suite d'un tableau sur le déplacement des héros? Le lecteur finit par se demander si l'auteure fait une distinction entre les termes «héros», «personnage» et «sujet».

Le cas d'imprécision le plus flagrant arrive cependant dans l'étude sur la position topographique du personnage féminin. Après avoir affirmé à la page 99 que les «sujettes» de ces romans comprennent, en séquence initiale, 55 célibataires, 20 fiancées, 10 mariées et 1 amante, l'auteure ajoute quelques lignes plus loin qu'on trouve, en séquence initiale, 34 mères. Cela ferait un nombre remarquable de mères célibataires... Faut-il conclure que les mères ne comptent pas comme «sujettes»? Que «sujette» serait synonyme d' «héroïne»? Et que dire lorsque, sept pages plus loin, on nous parle de «vingt-cinq cas de personnages féminins mariés en séquence initiale»?

Bref, les sections de cette étude qui se veulent les plus précises et scientifiques sont en réalité une collection de catégories et de statistiques vagues, souvent fort discutables. L'auteure évite toute possibilité de vérification, voire de compréhension complète, par le lecteur. De plus, il lui arrive de glisser subrepticement dans son texte des affirmations fortement teintées idéologiquement, comme : «Le roman du terroir... reproduit, en la dramatisant, l'idéologie bourgeoise essentiellement fondée sur la division sociale à commencer par l'inégalité de statut entre les hommes et les femmes». (À notre connaissance, cette inégalité n'a rien de spécifiquement bourgeois). De la même façon, elle explique le fait que, dans le roman du terroir, le taux de natalité est plus élevé chez les campagnards que chez les citadins, non pas par des raisons d'ordre pratique (ou romanesque), mais parce que «l'idéologie dominante (est) soucieuse, nous l'avons signalé, de maintenir la campagne dans sa fonction de réservoir de main-d'œuvre à bon marché» (p. 48). ${ }^{6}$

En somme, ce volume est souvent aussi naïvement idéologique que les romans qu'il étudie.

Devant tant de glissements et de lacunes, on pourrait être tenté d'interpréter l'épithète «systématique» du titre dans le sens péjoratif de «qui est péremptoire et dogmatique, préférant son système à toute autre raison». $\mathrm{Si}$ une telle réaction serait injuste, il reste que l'on pourrait mettre en doute le côté "méthodique» d'un ouvrage qui renferme tant de coquilles ou d'erreurs et qui semble parfois faire fi des mathématiques les plus élémentaires.

6. Par ailleurs, comment concilier cette affirmation de Janine Boynard-Frot au sujet des familles plus nombreuses à la campagne et le fait que bon nombre de romans de la terre racontent la tragédie d'un fils unique qui abandonne la terre, la laissant sans héritier? Voici un cas parmi d'autres où on voudrait pouvoir vérifier les chiffres fournis par notre critique. 